\title{
Turner syndrome with primary hyperparathyroidism
}

\author{
Jungmee Park, MD', \\ Yoo-Mi Kim, MD', \\ Jin-Ho Choi, MD', \\ Beom Hee Lee, MD', \\ Jong Ho Yoon, $\mathrm{MD}^{2}$, \\ Woon-Young Jeong, $\mathrm{MD}^{3}$, \\ Han-Wook Yoo, MD, PhD' \\ Departments of ${ }^{1}$ Pediatrics, \\ ${ }^{2}$ Surgery, and ${ }^{3}$ Pathology, \\ Asan Medical Center Children's \\ Hospital, University of Ulsan \\ College of Medicine, Seoul, Korea'
}

\begin{abstract}
Turner syndrome has multiple comorbidities such as osteoporosis, obesity, diabetes, hypothyroidism, and hypertension. As they are treatable conditions in Turner syndrome, early recognition and proper treatment should be needed. We report on a 23-year-old woman with Turner syndrome who presented with severe osteoporosis and hypercalcemia. Laboratory tests showed elevated levels of serum calcium and parathyroid hormone. Dual-energy X-ray absorptiometry showed severe osteopo-rosis (z score, -3.5). Ultrasound and ${ }^{99 \mathrm{~m}} \mathrm{Tc}$ scintigraphy of parathyroid glands showed an adenoma in the right inferior gland. She was diagnosed with primary hyperparathyroidism due to an adenoma of the parathyroid gland. After excision of the adenoma, the patient's serum calcium and parathyroid hormone levels returned to normal. Although only a few cases of Turners syndrome with primary hyperparathyroidism have been reported, hyperparathyroidism should be considered in cases of Turner syndrome with severe osteoporosis and hypercalcemia.
\end{abstract}

Keywords: Turner syndrome, Hyperparathyroidism, Osteoporosis, Hypercalcemia

\section{Introduction}

Turner syndrome is the most common chromosomal abnormality in females. It occurs in $1 / 2,500$ to $1 / 3,000$ live-born females and results from a total or partial absence of the $\mathrm{X}$ chromosome ${ }^{1)}$. The clinical manifestations are diverse with common features like short stature and amenorrhea. Turner syndrome is commonly diagnosed because of short stature in midchildhood, primary amenorrhea in adolescence, or in some cases, typical cardiac anomalies during infancy. Turner syndrome is accompanied by multiple medical problems such as cardiovascular diseases, kidney diseases, autoimmune thyroid diseases, diabetes mellitus, osteoporosis, and inflammatory bowel disease. Hearing loss and psychosocial problems are also common in Turner syndrome $e^{2,3)}$.

Hyperparathyroidism is characterized by the overactivity of the parathyroid glands. It can be classified as primary or secondary hyperparathyroidism. Primary hyperparathyroidism is a disease caused by an increase in parathyroid hormone secretion without a specific stimulus leading to hypercalcemia. The most common cause is single gland adenoma in postmenopausal women. Secondary hyperparathyroidism is caused by low blood calcium levels resulting in elevation of parathyroid hormone, for instance, vitamin D deficiency, chronic renal disease, and malabsorption, etc. ${ }^{4)}$.

The authors diagnosed primary hyperparathyroidism caused by parathyroid adenoma in 23-year-old patient with Turner syndrome based on incidental identification of hypercalcemia and severe osteoporosis.

\section{Case report}

A 23-year-old woman with Turner syndrome was hospitalized because of incidentally identified hypercalcemia during routine blood tests at out-patient clinic. She was diagnosed with Turner syndrome $(45, \mathrm{X})$ due to short stature at age 11 years and had received

Fax: $+82-2-473-3725$

E-mail: hwyoo@amc.seoul.kr 
recombinant human growth hormone (rhGH) for about 4 years. Since she was 13 years, she has been on estrogen priming and estrogen-progesterone cyclic therapy.

Her vital signs were normal with blood pressure of 112/74 $\mathrm{mmHg}$, heart rate of $80 \mathrm{bpm}$, respiratory rate of $20 / \mathrm{min}$, and body temperature of $36^{\circ} \mathrm{C}$. She was short in stature despite longterm therapy and overweight, measuring $151.2 \mathrm{~cm}$ (standard deviation score [SDS], -2.093) and weighing $55.4 \mathrm{~kg}$ (SDS, $-0.367)$. She showed typical signs of Turner syndrome, such as

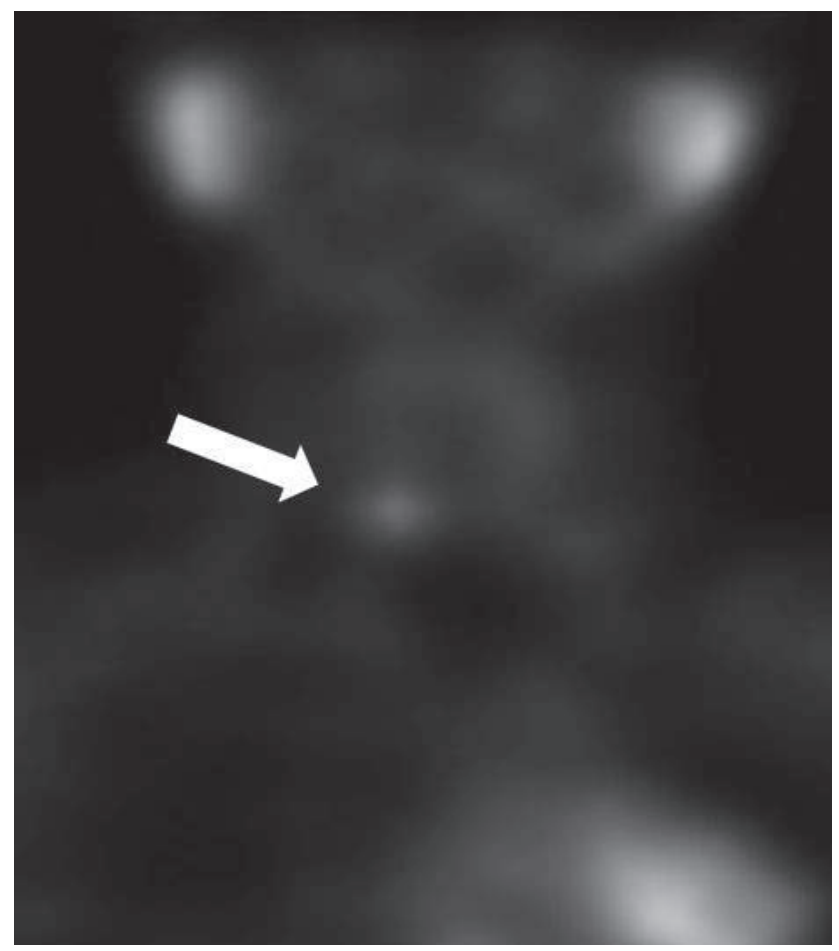

Fig. 1. Parathyroid scintigraphy of the patient demonstrated adenoma in the right inferior parathyroid gland (white arrow).

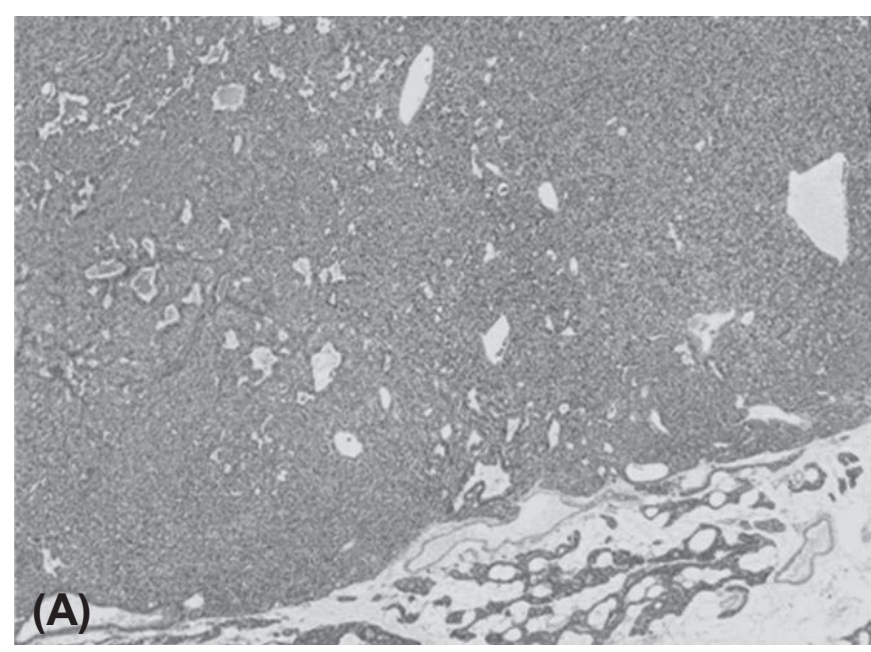

high arched palate, webbed neck, shield chest deformity, and cubitus valgus on both sides. Mild scoliosis was noted in simple T-L spine radiographs. Tanner stage was breast III and pubic hair II.

The laboratory profiles demonstrated normal complete blood count and electrolytes. Serum calcium and ionized calcium levels were elevated to $11.2 \mathrm{mg} / \mathrm{dL}$ (8.4 to $10.2 \mathrm{mg} / \mathrm{dL}$ ) and $5.07 \mathrm{mg} / \mathrm{dL}$ (3.9 to $4.5 \mathrm{mg} / \mathrm{dL}$ ), respectively, while phosphorous and alkaline phosphatase were normal $(2.6 \mathrm{mg} / \mathrm{dL}$ and 107 $\mathrm{IU} / \mathrm{L}$, respectively). Thyroid stimulating hormone and free $\mathrm{T} 4$ were both within normal range $(3.3 \mu \mathrm{U} / \mathrm{mL}$ and $1.4 \mathrm{ng} / \mathrm{dL}$, respectively). Serum parathyroid hormone level increased up to $159 \mathrm{pg} / \mathrm{mL}$ ( 9 to $65 \mathrm{pg} / \mathrm{mL}$ ), whereas 25 -hydroxyvitamin D3 decreased to $15.1 \mathrm{ng} / \mathrm{mL}$ (20 to $100 \mathrm{ng} / \mathrm{mL}$ ). Hypergonadotropic hypogonadism was present in spite of estrogen/progesterone replacement therapy (follicle stimulating hormone of $32.4 \mathrm{mIU} /$ $\mathrm{mL}$, luteinizing hormone of $10.5 \mathrm{mIU} / \mathrm{mL}$, and estradiol of 21.2 $\mathrm{pg} / \mathrm{mL}$ ). Urinalysis indicated mild occult hematuria. Increase in both calcium/creatinine $(\mathrm{Cr})$ ratio $(0.211 \mathrm{mg} / \mathrm{mg}$; Cr, < 0.14 $\mathrm{mg} / \mathrm{mg})$ and phosphorus/Cr ratio $(0.985 \mathrm{mg} / \mathrm{mg}$; Cr, 0.21 to 0.75 $\mathrm{mg} / \mathrm{mg}$ ) were observed.

Additional tests were carried out to exclude multiple endocrine neoplasia, however, all of the tests were normal: serum and urine catecholamine level and calcitonin were within normal range and abdomen ultrasonography did not show any specific findings in the pancreas and adrenal glands, nor any stone-related abnormalities in both kidneys. Dual-energy X-ray absorptiometry (DEXA) scan revealed osteoporosis with bone mineral density (BMD) of the spine (L1-L4) $\left(0.736 \mathrm{~g} / \mathrm{cm}^{2} ; \mathrm{z}\right.$ score, -3.5$)$ and femur $\left(0.651 \mathrm{~g} / \mathrm{cm}^{2} ; \mathrm{z}\right.$ score, -2.7$)$. In parathyroid scintigraphy, a locally increased activity in the lower right lobe of a parathyroid was not washed out even after 2 hours (Fig. 1). An oval-shaped, low attenuated, hypervascular mass in the lower pole of the right parathyroid was observed in neck ultrasonography measuring $1.2 \mathrm{~cm} \times 0.8 \mathrm{~cm} \times 0.6 \mathrm{~cm}$, suggesting

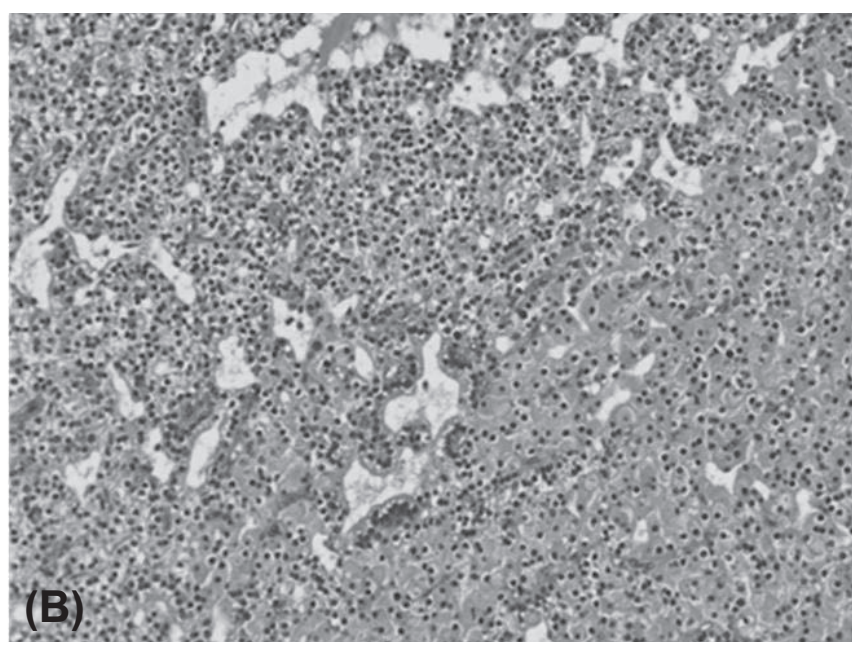

Fig. 2. Microscopic findings of the excised parathyroid adenoma of patient. (A) The tumor is well circumscribed and lack of stromal fat, which is abundant in the normal gland at the periphery. The tumor cells are arranged in solid sheets or follicular structure $(H \& E, \times 40)$. (B) The tumor is predominantly composed of chief cells intermingled with oxyphilic cells $(H \& E, \times 200)$. 
parathyroid adenoma.

The lower right parathyroid gland was completely resected, and pathologic findings confirmed the diagnosis of parathyroid gland adenoma measuring $1.3 \mathrm{~cm} \times 0.9 \mathrm{~cm} \times 0.8 \mathrm{~cm}$ (Fig. 2). Two days after operation, serum calcium level, ionized calcium and parathyroid hormone levels were normalized (Fig. 3). After discharge, the subject has been monitored by laboratory tests such as serum chemistry and urine calcium/Cr ratio until now and follow up image is under considered.

\section{Discussion}

This study reports primary hyperparathyroidism in an adult patient with Turner syndrome, which has been reported to be extremely rare $^{5-9)}$. Life-long monitoring is required in patients with Turner syndrome because of its various clinical manifestations such as cardiovascular disease, autoimmune thyroid disease, diabetes, and deafness ${ }^{2}$. Osteoporosis in Turner syndrome is caused by estrogen deficiency resulting from gonadal dysgenesis, genetic factors related to osteogenesis in the X chromosome such as $S H O X$ gene haploinsufficiency, and decrease in androgen and vitamin D insufficiency ${ }^{10-13)}$. In previous studies, it has been reported that osteoporosis occurs more frequently in patients with Turner syndrome compared to normal control ${ }^{13,14)}$. In patients with Turner syndrome under estrogen replacement therapy, volumetric BMD was similar to that of normal control ${ }^{15)}$. However, without proper and timely estrogen treatment, bone density drops due to rapid loss of trabecular bone tissue and incidence of fractures increased ${ }^{16)}$.
Therefore, it is important to conduct regular monitoring of BMD and estrogen replacement therapy to prevent osteoporosis in patients with Turner syndrome ${ }^{17)}$. The previous study in Denmark demonstrated that DEXA measurements revealed that $28 \%$ of adult Turner syndrome patients showed osteopenia and $23 \%$ of osteoporosis ${ }^{13)}$. In addition, serum calcium and 25-hydroxyvitamin D3 levels decreased and parathyroid hormone (PTH) level increased compared to control ${ }^{13)}$. Decrease in 25-hydroxyvitamin D3 levels in Turner syndrome may be due to a lower degree of physical activity resulting in the lack of sunlight exposure and insufficient uptake of vitamin $D^{18)}$.

This case showed persistent hypercalcemia as well as severe osteoporosis, which is very unusual in Turner syndrome. It was turned out that she had primary hyperparathyroidism due to parathyroid gland adenoma. Primary hyperparathyroidism contributed to aggravating her osteoporosis. To date, only a few Turner syndrome patients have been reported to be associated with primary hyperparathyroidism. Including our case, only 6 cases of primary hyperparathyroidism in Turner syndrome have been reported ${ }^{5-9)}$. Most patients manifested osteoporosis, hyperacalcemia, and parathyroid adenoma (Table 1). The underlying mechanism of development remained to be discovered. Low 25-hydroxyvitamin D levels are related to higher plasma PTH levels and subsequently exacerbate primary hyperparathyroidism ${ }^{19,20)}$.

In conclusion, we noticed primary hyperparathyroidism in Turner syndrome patients presented with hypercalcemia and severe osteoporosis. It should be considered that the patients with Turner syndrome with persistent hypercalcemia and severe

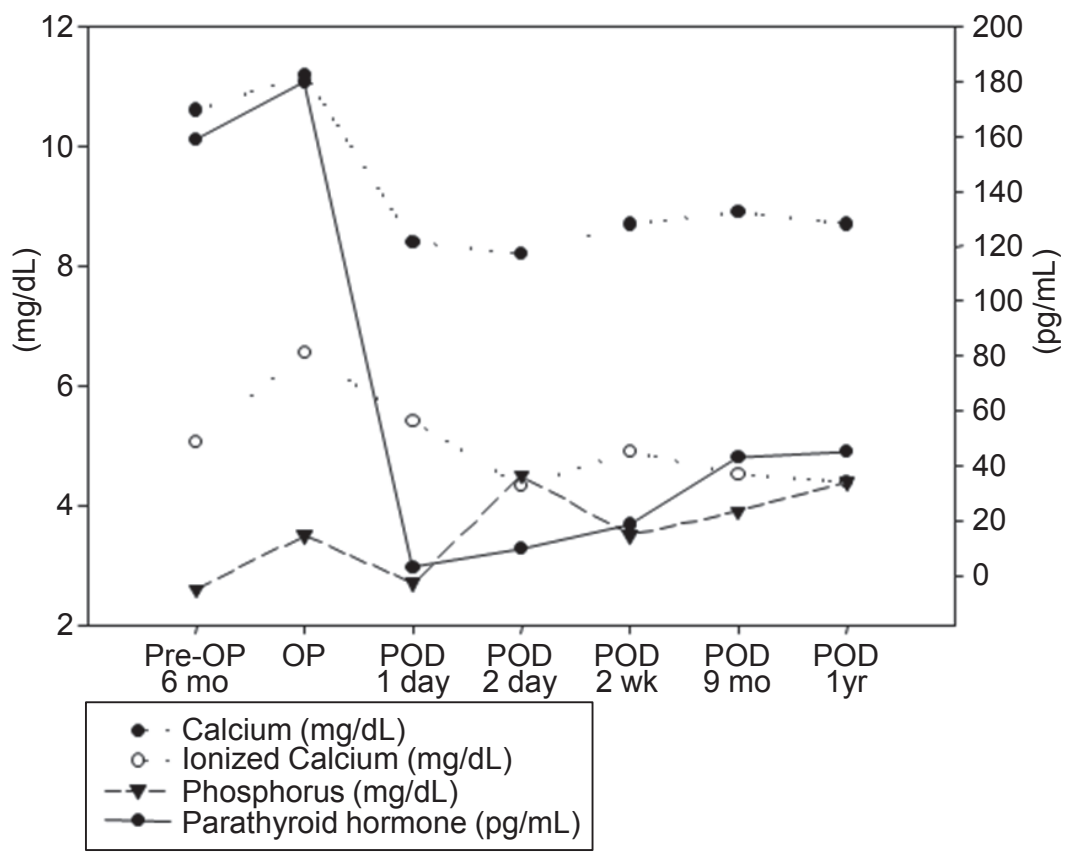

Fig. 3. Comparison of laboratory findings before and after operation. Pre-OP, pre-operation; POD, postoperation day. 
Table 1. Six Turner syndrome patients reported with hyperparathyroidism

\begin{tabular}{|c|c|c|c|c|c|c|}
\hline Variable & Case 1 & Case 2 & Case 3 & Case 4 & Case 5 & Case 6 \\
\hline Age at diagnosis (yr) & 37 & 14 & 50 & 46 & 54 & 23 \\
\hline Karyotype & $46, X, i(X)(q 10) / 45, X$ & $45, x$ & $45, x$ & $45, X$ & $45, X / 46, X X$ & $45, x$ \\
\hline Presentation & $\begin{array}{l}\text { Bone pain } \\
\text { Osteoporosis }\end{array}$ & $\begin{array}{l}\text { Abdominal pain } \\
\text { Renal stone }\end{array}$ & $\begin{array}{l}\text { Bone pain } \\
\text { Osteoporosis }\end{array}$ & $\begin{array}{l}\text { Bone pain } \\
\text { Osteitis fibrosia }\end{array}$ & $\begin{array}{l}\text { No symptoms } \\
\text { Bone cyst in X-ray } \\
\text { Osteitis fibrosia }\end{array}$ & $\begin{array}{l}\text { No symptoms } \\
\text { Hypercalcemia in } \\
\text { lab tests }\end{array}$ \\
\hline \multicolumn{7}{|l|}{ Laboratory findings } \\
\hline Calcium (mg/dL) & 10.0 & 13.5 & 10.8 & 14.3 & 11.8 & 11.2 \\
\hline Phosphorus (mg/dL) & 2.7 & ND & ND & 1.8 & 1.7 & 2.6 \\
\hline $\begin{array}{l}\text { PTH }(\mathrm{pg} / \mathrm{mL}), \\
(9-65 \mathrm{pg} / \mathrm{mL})\end{array}$ & 188 & 86 & 418 & 1,029 & 1,704 & 159 \\
\hline $\begin{array}{c}\text { 25(OH)D3 (ng/mL), } \\
(20-100 \mathrm{ng} / \mathrm{mL})\end{array}$ & ND & 25 & ND & ND & Undetectable & 15.1 \\
\hline Outcome & Parathyroidectomy & Parathyroidectomy & Parathyroidectomy & $\begin{array}{c}\text { Death due to } \\
\text { necrotizing } \\
\text { pancreatitis }\end{array}$ & $\begin{array}{l}\text { Parathyroidectomy } \\
\text { Celiac disease }\end{array}$ & Parathyroidectomy \\
\hline Diagnosis & Adenoma & Adenoma & Adenoma & $\begin{array}{l}\text { Not proven by } \\
\text { pathology }\end{array}$ & Adenoma & Adenoma \\
\hline References & Paul et al. ${ }^{5)}$ & Francois et al. $\left.{ }^{6}\right)$ & Shirzad et al. ${ }^{7)}$ & Kishida et al. ${ }^{8)}$ & Sleiman et al.9) & Our case \\
\hline
\end{tabular}

PTH, parathyroid hormone; 25(OH)D3, 25-hydroxy-vitamin D3; ND, not documented.

osteoporosis might have primary hyperparathyroidism.

\section{Conflict of interest}

No potential conflict of interest relevant to this article was reported.

\section{References}

1. Sybert VP, McCauley E. Turner's syndrome. N Engl J Med 2004;351:1227-38.

2. Conway GS. Considerations for transition from paediatric to adult endocrinology: women with Turner's syndrome. Growth Horm IGF Res 2004;14 Suppl A:S77-84.

3. Jin HY, Choi JH, Lee BH, Yoo HW. Predictive factors of diabetes and hypertension in adult Turner syndrome. J Korean Soc Pediatr Endocrinol 2010;15:187-92.

4. Fraser WD. Hyperparathyroidism. Lancet 2009;374:145-58.

5. Paul TV, Dinakar J, Thomas N, Mathews SS, Shanthly N, Nair A. A case of Turner syndrome with hyperparathyroidism in an adult. Ear Nose Throat J 2008;87:110-2.

6. Francois I, Proesmans W, de Zegher F. Case of the month: a girl with Ullrich-Turner syndrome, nephrolithiasis and hypercalcaemia. Eur J Pediatr 1996;155:615-6.

7. Shirzad N, Tehrani MR, Soltani A. A rare association of hyperparathyroidism and Turner's syndrome: a case report. Endokrynol Pol 2008;59:232-4.

8. Kishida M, Otsuka F, Mimura Y, Ogura T, Makino H. A lethal complication, acute necrotizing pancreatitis, of Turner's Syndrome with primary hyperparathyroidism. Endocr J 2003;50:835-6.

9. Sleiman I, Godi D, Villanacci V, Pelizzari G, Balestrieri GP. Osteitis fibrosa cystica, coeliac disease and Turner syndrome: a case report. Dig Liver Dis 2004;36:486-8.

10. Rubin K. Turner syndrome and osteoporosis: mechanisms and prognosis. Pediatrics 1998;102(2 Pt 3):481-5.

11. Oliveira CS, Alves C. The role of the SHOX gene in the pathophysiology of Turner syndrome. Endocrinol Nutr 2011;58:433-42.

12. Ross JL, Scott C Jr, Marttila P, Kowal K, Nass A, Papenhausen P, et al. Phenotypes associated with SHOX deficiency. J Clin Endocrinol Metab 2001;86:5674-80.

13. Gravholt CH, Lauridsen AL, Brixen K, Mosekilde L, Heickendorff L, Christiansen IS. Marked disproportionality in bone size and mineral, and distinct abnormalities in bone markers and calcitropic hormones in adult turner syndrome: a cross-sectional study. J Clin Endocrinol Metab 2002;87:2798-808.

14. Bakalov VK, Axelrod L, Baron J, Hanton L, Nelson LM, Reynolds JC, et al. Selective reduction in cortical bone mineral density in turner syndrome independent of ovarian hormone deficiency. J Clin Endocrinol Metab 2003;88:5717-22..

15. Bertelloni S, Cinquanta L, Baroncelli GI, Simi P, Rossi S, Saggese G. Volumetric bone mineral density in young women with Turner's syndrome treated with estrogens or estrogens plus growth hormone. Horm Res 2000;53:72-6.

16. Bakalov VK, Bondy CA. Fracture risk and bone mineral density in Turner syndrome. Rev Endocr Metab Disord 2008;9:145-51.

17. Hanton L, Axelrod L, Bakalov V, Bondy CA. The importance of estrogen replacement in young women with Turner syndrome. J Womens Health (Larchmt) 2003;12:971-7.

18. Landin-Wilhelmsen K, Bryman I, Windh M, Wilhelmsen L. Osteoporosis and fractures in Turner syndromeimportance of growth promoting and oestrogen therapy. Clin Endocrinol (Oxf) 1999;51:497-502. 
19. Silverberg SJ, Shane E, Dempster DW, Bilezikian JP. The effects of vitamin $D$ insufficiency in patients with primary hyperparathyroidism. Am J Med 1999;107:561-7.

20. Moosgaard B, Vestergaard P, Heickendorff L, Melsen F, Christiansen P, Mosekilde L. Plasma 25-hydroxyvitamin
D and not 1,25-dihydroxyvitamin D is associated with parathyroid adenoma secretion in primary hyperparathyroidism: a cross-sectional study. Eur J Endocrinol 2006;155:237-44. 